\title{
Predictors of extended length of stay, discharge to inpatient rehab, and hospital readmission following elective lumbar spine surgery: introduction of the Carolina-Semmes Grading Scale
}

\author{
Matthew J. McGirt, MD, ${ }^{1}$ Scott L. Parker, MD, ${ }^{2}$ Silky Chotai, MD, ${ }^{2}$ Deborah Pfortmiller, PhD, ${ }^{1}$ \\ Jeffrey M. Sorenson, MD, ${ }^{3}$ Kevin Foley, MD, ${ }^{3}$ and Anthony L. Asher, MD ${ }^{1}$ \\ 1Department of Neurological Surgery, Carolina Neurosurgery and Spine Associates and Neuroscience Institute, Carolinas \\ Healthcare System, Charlotte, North Carolina; '2Department of Neurological Surgery and Orthopaedic Surgery, Vanderbilt Spine \\ Center, Vanderbilt University Medical Center, Nashville; and ${ }^{3}$ Department of Neurosurgery, University of Tennessee Health \\ Sciences Center, Semmes Murphey Neurologic \& Spine Institute, Memphis, Tennessee
}

OBJECTIVE Extended hospital length of stay (LOS), unplanned hospital readmission, and need for inpatient rehabilitation after elective spine surgery contribute significantly to the variation in surgical health care costs. As novel payment models shift the risk of cost overruns from payers to providers, understanding patient-level risk of LOS, readmission, and inpatient rehabilitation is critical. The authors set out to develop a grading scale that effectively stratifies risk of these costly events after elective surgery for degenerative lumbar pathologies.

METHODS The Quality and Outcomes Database (QOD) registry prospectively enrolls patients undergoing surgery for degenerative lumbar spine disease. This registry was queried for patients who had undergone elective 1- to 3-level lumbar surgery for degenerative spine pathology. The association between preoperative patient variables and extended postoperative hospital LOS (LOS $\geq 7$ days), discharge status (inpatient facility vs home), and 90-day hospital readmission was assessed using stepwise multivariate logistic regression. The Carolina-Semmes grading scale was constructed using the independent predictors for LOS (0-12 points), discharge to inpatient facility (0-18 points), and 90-day readmission (0-6 points), and its performance was assessed using the QOD data set. The performance of the grading scale was then confirmed separately after using it in 2 separate neurosurgery practice sites (Carolina Neurosurgery \& Spine Associates [CNSA] and Semmes Murphey Clinic).

RESULTS A total of 6921 patients were analyzed. Overall, 290 (4.2\%) patients required extended LOS, 654 (9.4\%) required inpatient facility care/rehabilitation on hospital discharge, and $474(6.8 \%)$ were readmitted to the hospital within 90 days postdischarge. Variables that remained as independently associated with these unplanned events in multivariate analysis included age $\geq 70$ years, American Society of Anesthesiologists Physical Classification System class $>$ III, Oswestry Disability Index score $\geq 70$, diabetes, Medicare/Medicaid, nonindependent ambulation, and fusion. Increasing point totals in the Carolina-Semmes scale effectively stratified the incidence of extended LOS, discharge to facility, and readmission in a stepwise fashion in both the aggregate QOD data set and when subsequently applied to the CNSA/ Semmes Murphey practice groups.

CONCLUSIONS The authors introduce the Carolina-Semmes grading scale that effectively stratifies the risk of prolonged hospital stay, need for postdischarge inpatient facility care, and 90-day hospital readmission for patients undergoing first-time elective 1- to 3-level degenerative lumbar spine surgery. This grading scale may be helpful in identifying patients who may require additional resource utilization within a global period after surgery.

https://thejns.org/doi/abs/10.3171/2016.12.SPINE16928

KEY WORDS QOD; readmission; inpatient rehabilitation; discharge; lumbar spine

ABBREVIATIONS ASA = American Society of Anesthesiologists Physical Classification System; AUC = area under the curve; LOS = length of stay; NRS = numeric rating scale; ODI = Oswestry Disability Index; $\mathrm{QOD}=$ Quality and Outcomes Database; ROC = receiver operating characteristic.

SUBMITTED August 9, 2016. ACCEPTED December 30, 2016.

INCLUDE WHEN CITING Published online May 12, 2017; DOI: 10.3171/2016.12.SPINE16928. 
$\mathrm{T}$ HE costs associated with spine surgery are increasing exponentially. In an attempt to curb increasing expenditures, the Centers for Medicare and Medicaid Service, private insurers, and other health care purchasers have initiated several cost containment and quality improvement measures. ${ }^{5,9,37}$ Perhaps the most common among these novel payment and quality improvement programs is capitated bundled care contracting for spine surgery and other health care services. These contracts require hospitals and their physicians to "bundle" facility and professional charges for necessary care throughout a defined longitudinal episode of care, and to assume all risk of cost/utilization overruns. In these emerging reimbursement models, patient safety outliers, low quality of care, and health care utilization overruns are events that represent financial risk to the physician and hospital alike, a risk once held exclusively by the payer.

Extended length of hospital stay (LOS), $8,43,44$ need for inpatient rehabilitation at the time of discharge, and unplanned hospital readmission are significant contributors to the variation in surgical health care costs after elective spine surgery. ${ }^{2-4,7,19,33,42,45,46}$ Costs associated with each additional day in the hospital average approximately $\$ 1000 .{ }^{47}$ Post-acute care facilities costs can exceed $\$ 10,000$ per patient in routine cases. Hospital readmission rates range from $2.5 \%$ to $10 \%$, resulting in Medicare expenditures of $\$ 17.8$ billion a year. ${ }^{35}$

Even a small proportion of patients experiencing expensive, unanticipated outcomes in bundled payment programs can consume a large percentage of a service line's capitated revenue. Therefore, in order for capitated or bundled payment models to be financially sustainable for hospitals and surgeons alike, providers must be able to stratify the risk of unplanned events at the individual patient level up front. Such risk assessment is essential in defining whether individual patients should be included in specific bundled services, or when allocating preventative resources to address modifiable factors in "high-risk" patients. For obvious reasons, such information is essential when negotiating more complex bundled payments that are tiered per patient risk profile.

To date, there has been no comprehensive, prospective analysis of patient data with the primary intent of understanding the factors associated with increased risk of hospital LOS, need for inpatient rehabilitation, and hospital readmission after lumbar spine surgery. We set out to develop a grading scale that effectively stratifies risk of these costly events after elective surgery for degenerative lumbar pathologies.

\section{Methods \\ Patient Population}

The Quality and Outcomes Database (QOD) is a prospective patient-reported outcomes registry that enrolls patients undergoing elective spine surgery from 74 hospitals in 26 US states via representative sampling., 5,6,31 Reasons for exclusion from the database are spinal infection, tumor, fracture, traumatic dislocation, deformity, pseudarthrosis, recurrent multilevel stenosis, and neurological paralysis due to preexisting spinal disease or injury, age younger than 18 years, and incarceration. For the purposes of this study, patients with a diagnosis of deformity or disc herniation were excluded. Patients undergoing 1- to 3-level lumbar surgery for stenosis, spondylolisthesis, symptomatic mechanical disc collapse, or revision surgery, including recurrent same-level disc herniation and adjacent-segment disease, were eligible for inclusion. Furthermore, to capture all information relevant to the outcomes in question, only cases that had complete data for LOS, hospital readmission, and discharge location were included.

\section{Measures}

Patient demographic characteristics, including age, body mass index, sex, race, education level, insurance, and existing comorbidities, were prospectively collected for each patient enrolled in the registry. Additional preoperative patient data included clinical presentation, diagnosis, perioperative medical care, and spine surgery complications. Patient-reported outcomes were collected using standard-of-care outcomes questionnaires across all sites and included the back and leg pain numeric rating scale (NRS), ${ }^{28}$ the Oswestry Disability Index (ODI), ${ }^{18}$ and the EQ-5D. ${ }^{17}$ Patient-level risk variables outlined in the data collection for this project were extended LOS ( $\geq 7$ days), discharge status (inpatient facility vs home), and 90-day hospital readmission. We used the upper limit of the previously reported range (3-7 days) to define the extended hospital LOS. ${ }^{21,39,40,48}$

HIPAA (Health Insurance Portability and Accountability Act)-trained data coordinators/extractors at each site entered data through a secure password-protected web-based portal (REDCap [Research Electronic Data Capture]) into a national aggregate database. ${ }^{23}$ Data completeness and accuracy were assessed via automated and manual methods at the Vanderbilt Institute for Medicine and Public Health. Diagnostic accuracy was maintained through periodic surgeon-led self-audits that sought to correlate entered data with radiographic and clinical records. The accuracy of diagnosis and treatment variables was confirmed via medical record audit. ${ }^{5}$

The prospectively collected QOD observational registry records of patient baseline demographics, surgical data, 30-day morbidity, and 3- and 12-month patient-reported outcomes were queried and analyzed in March 2016.

\section{Statistical Analysis}

The mean (SD) or median (interquartile range [IQR]) for continuous variables and frequency for categorical variables were computed. Stepwise multivariate logistic regression was used to identify significant preoperative patient, disease, and treatment factors that were independently associated with the 3 outcome variables: extended LOS, discharge status, and 90-day hospital readmission. To derive the Carolina-Semmes grading scale, the values of the resulting odds ratio, rounded to the nearest whole number for each logistic regression, were used to determine the number of points assigned to a given significant predictor. For development, the grading scale was applied to the outcomes data set provided by the 74 QOD hospital centers to determine if increasing point totals effectively 
stratified an increasing risk of events. For validation, the grading scale was then applied to Carolina Neurosurgery \& Spine Associates and Semmes Murphey Clinic QOD outcomes data sets collected from 2010 to 2015. Receiver operating characteristic (ROC) curve analysis was used to examine the sensitivity and specificity of the binary classification outcomes. The area under the curve (AUC) is reported as a comparison with a probability of 0.50 . The statistical package, SPSS (version 23, IBM) was used to analyze the data. A $p$ value of $<0.05$ was considered statistically significant.

\section{Results}

Of a total of 13,987 patients undergoing elective spine surgery for degenerative lumbar disease, 5407 patients were excluded due to excluded diagnosis; 1229 were excluded due to missing outcome measures including LOS, discharge, and 90-day readmission; 430 patients were excluded due to missing predictor variables. Therefore, 6921 patients met the inclusion criteria and were further analyzed. Table 1 summarizes the demographics of the study cohort. Overall, $290(4.2 \%)$ patients required extended LOS, $654(9.4 \%)$ required inpatient facility care/rehabilitation facility on hospital discharge, and 474 (6.8\%) 90day hospital readmission.

In a stepwise multivariable logistic regression analyses, variables that were independently associated with the extended LOS were age $\geq 70$ years, ODI score $\geq 70$, American Society of Anesthesiologists (ASA) Physical Classification System class > III, diabetes, preoperative assisted ambulation, and fusion (Table 2). Variables that were independently associated with the need for inpatient facility care/rehabilitation at hospital discharge included age $\geq$ 70 years, ODI $\geq 70$, ASA class $>$ III, Medicare/Medicaid insurance, diabetes, preoperative assisted ambulation, and

TABLE 1. Preoperative variables proportion within the QOD data set

\begin{tabular}{lc}
\hline \multicolumn{1}{c}{ Preop Variables } & Proportion of Population \\
\hline Age (<70 vs $\geq 70$ ) & $69.6 \%$ vs $30.4 \%$ \\
\hline BMI (<35 vs $\geq 35$ ) & $78.0 \%$ vs $22.0 \%$ \\
\hline NRS back pain (<9 vs $\geq 9$ ) & $73.2 \%$ vs $26.8 \%$ \\
\hline NRS leg pain (<9 vs $\geq 9$ ) & $70.4 \%$ vs $29.6 \%$ \\
\hline ODI (<70 vs $\geq 70)$ & $89.8 \%$ vs $10.2 \%$ \\
\hline EQ-5D (>0.30 vs $\leq 0.30$ ) & $87.3 \%$ vs $12.7 \%$ \\
\hline ASA (Classes I-III vs IV \& V) & $98.4 \%$ vs $1.6 \%$ \\
\hline Sex (M vs F) & $49.9 \%$ vs $50.1 \%$ \\
\hline Race (Caucasian vs other) & $90.7 \%$ vs $9.3 \%$ \\
\hline Education (HS grad vs beyond HS) & $50.5 \%$ vs $49.5 \%$ \\
\hline Private insurance (no vs yes) & $79.4 \%$ vs $20.6 \%$ \\
\hline Dominant symptom (back vs other) & $24.7 \%$ vs $75.3 \%$ \\
\hline Motor defict (no vs yes) & $74.3 \%$ vs $25.7 \%$ \\
\hline Ambulation (independent vs assisted) & $82.8 \%$ vs $17.2 \%$ \\
\hline Arthrodesis (no vs yes) & $47.6 \%$ vs $52.4 \%$ \\
\hline Surgery level (single vs multiple) & $30.6 \%$ vs $69.4 \%$ \\
\hline
\end{tabular}

$\mathrm{BMI}=$ body mass index; HS = high school.
TABLE 2. Stepwise multivariate logistic regression of extended LOS using significant bivariate preoperative variables $(p<0.010)$

\begin{tabular}{lccrcc}
\hline \multicolumn{1}{c}{ Predictor } & $\begin{array}{c}\text { Beta } \\
\text { Coefficient }\end{array}$ & $\begin{array}{c}\text { SE for } \\
\text { Beta }\end{array}$ & $\begin{array}{c}\text { Wald's } \\
\chi^{2}\end{array}$ & $\begin{array}{c}p \\
\text { Value }\end{array}$ & $\begin{array}{c}\text { Odds } \\
\text { Ratio }\end{array}$ \\
\hline Constant & -4.488 & 0.160 & 786.316 & $<0.001$ & NA \\
\hline Fusion (no vs yes) & 1.200 & 0.1500 & 63.995 & $<0.001$ & 3.320 \\
\hline $\begin{array}{c}\text { ASA (Classes I-III vs } \\
\text { IV \& V) }\end{array}$ & 0.822 & 0.331 & 6.178 & 0.013 & 2.274 \\
\hline Age (<70 vs $\geq 70)$ & 0.544 & 0.137 & 15.776 & $<0.001$ & 1.723 \\
\hline ODI (<70 vs $\geq 70)$ & 0.520 & 0.174 & 8.911 & 0.003 & 1.682 \\
\hline $\begin{array}{l}\text { Diabetes (no vs yes) } \\
\text { Ambulation (indepen- } \\
\text { dent vs assisted) }\end{array}$ & 0.379 & 0.145 & 6.878 & 0.009 & 1.461 \\
\hline
\end{tabular}

NA = not applicable.

Overall model evaluation: $\chi^{2}=6.571, p=0.010$.

Six preoperative variables remained independently associated with extended LOS ( $\geq 7$ days) after elective 1 - to 3 -level lumbar surgery.

fusion (Table 3). Variables that were independently associated with the 90-day hospital readmission included ODI score $\geq 70$, ASA class $>$ III, Medicare/Medicaid insurance, and preoperative assisted ambulation (Table 4).

The values of the resulting odds ratio for each logistic regression were used to determine the number of points assigned to a given significant predictor. The CarolinaSemmes grading scale was constructed using the significant independent predictors for LOS (0-12 points), discharge to inpatient facility (0-18 points), and 90-day readmission ( $0-6$ points) (Table 5$)$.

The Carolina-Semmes scale effectively stratified the incidence of extended LOS, discharge to facility, and readmission in the overall QOD data set (Figs. 1-3). For the risk of requiring an extended LOS longer than 7 days, Grade $0-3$ patients had very little (2.4\%) likelihood of

TABLE 3. Stepwise multivariate logistic regression of discharge to facility using significant bivariate preoperative variables $(p<$ 0.010)

\begin{tabular}{lrrrcc}
\hline \multicolumn{1}{c}{ Predictor } & $\begin{array}{c}\text { Beta } \\
\text { Coefficient }\end{array}$ & $\begin{array}{c}\text { SE for } \\
\text { Beta }\end{array}$ & $\begin{array}{c}\text { Wald's } \\
\chi^{2}\end{array}$ & $\begin{array}{c}p \\
\text { Value }\end{array}$ & $\begin{array}{c}\text { Odds } \\
\text { Ratio }\end{array}$ \\
\hline Constant & -4.536 & 0.179 & 644.020 & $<0.001$ & NA \\
\hline Fusion (no vs yes) & 1.208 & 0.108 & 124.379 & $<0.001$ & 3.345 \\
\hline $\begin{array}{c}\text { ASA (Classes I-III vs } \\
\text { IV \& V) }\end{array}$ & 1.294 & 0.246 & 27.677 & $<0.001$ & 3.647 \\
\hline Age (<70 vs $\geq 70)$ & 1.080 & 0.110 & 95.620 & $<0.001$ & 2.945 \\
\hline ODI (<70 vs $\geq 70)$ & 0.585 & 0.133 & 19.344 & $<0.001$ & 1.796 \\
\hline $\begin{array}{l}\text { Diabetes (no vs yes) } \\
\text { Ambulation (indepen- } \\
\text { dent vs assisted) }\end{array}$ & 0.627 & 0.107 & 34.375 & $<0.001$ & 1.871 \\
\hline $\begin{array}{c}\text { Private Insurance } \\
\text { (yes vs no) }\end{array}$ & 0.754 & 0.106 & 68.013 & $<0.001$ & 2.397 \\
\hline
\end{tabular}

Overall model evaluation: $\chi^{2}=4.939, p=0.026$.

Seven preoperative variables remained independently associated with requirement of inpatient rehabilitation/skilled nursing facility care after elective 1- to 3-level lumbar surgery. 
TABLE 4. Stepwise multivariate logistic regression of unplanned 90-day hospital readmission using significant bivariate preoperative variables $(p<0.010)$

\begin{tabular}{lrrrrr}
\hline \multicolumn{1}{c}{ Predictor } & $\begin{array}{c}\text { Beta } \\
\text { Coefficient }\end{array}$ & $\begin{array}{c}\text { SE for } \\
\text { Beta }\end{array}$ & Wald's $\chi^{2}$ & Value & $\begin{array}{c}\text { Odds } \\
\text { Ratio }\end{array}$ \\
\hline Constant & -2.622 & 0.075 & 1237.371 & $<0.001$ & NA \\
\hline $\begin{array}{l}\text { ASA (Classes I-III vs } \\
\text { IV \& V) }\end{array}$ & 0.603 & 0.296 & 4.135 & 0.042 & 1.827 \\
\hline ODI (<70 vs $\geq 70)$ & 0.553 & 0.141 & 15.373 & $<0.001$ & 1.739 \\
\hline $\begin{array}{l}\text { Private Insurance } \\
\text { (yes vs no) }\end{array}$ & 0.374 & 0.106 & 11.393 & $<0.001$ & 1.453 \\
\hline $\begin{array}{c}\text { Ambulation (indepen- } \\
\text { dent vs assisted) }\end{array}$ & 0.342 & 0.123 & 7.760 & 0.005 & 1.408 \\
\hline
\end{tabular}

Overall model evaluation: $\chi^{2}=3.623, p=0.057$.

Four preoperative variables remained independently associated with 90 -day readmission after elective 1 - to 3 -level lumbar surgery.

extended LOS; Grade 4-7 patients, moderate (7.1\%) likelihood; and Grade 8-12 patients had a more significant (18.3\%) likelihood (Fig. 1). For risk of requiring discharge to a rehabilitation facility, Grade $0-4$ patients had very little $(2.5 \%)$ incidence; Grade 5-12 patients, moderate (12\%) incidence; and Grade 13-18 patients had a significant (65\%) incidence (Fig. 2). Similarly, for risk of hospital readmission, Grade $0-2$ patients had very little $(6.2 \%)$ incidence; Grade 3-4 patients, moderate (13\%) incidence; and Grade 5-6 patients had a significant (25\%) incidence (Fig. 3).

To determine the validity of the grading scale, it was applied to patients from the Carolina Neurosurgery \& Spine Associates and Semmes Murphey Clinic undergoing 1- to 3-level surgery for QOD diagnoses. In these practice groups, the grading scale effectively stratified the risk of each event (Fig. 4).

The AUC of the ROC curve analysis for each outcome variable of interest was examined to compare the predictability of the grading scale against a $50 / 50$ probability. The AUC for extended LOS was 0.686 ( $\mathrm{p}<0.001$ ), for discharge to facility it was $0.731(\mathrm{p}<0.001)$, and for 90 day readmission it was $0.583(\mathrm{p}<0.001)$.

\section{Discussion}

As payment models shift the risk of cost-of-care overruns from payers to providers, understanding patient-level risk of LOS, readmission, and inpatient rehabilitation is critically important. Here, we introduce a novel grading scale (the Carolina-Semmes grading scale) that effectively stratifies the risk of prolonged LOS, need for postdischarge inpatient facility care, and 90-day hospital readmissions utilizing multicenter prospectively collected patient care data. Age $\geq 70$ years, ASA class $>$ III, back-related disability $(\mathrm{ODI}) \geq 70$, diabetes, Medicare/Medicaid, lack of independent ambulation, and fusion were independent risk factors for these unplanned events after elective spine surgery. By incorporating these preoperative risk factors in our predictive model, the Carolina-Semmes grading scale effectively stratified the risk of these unplanned events when applied to the development data set from 74
TABLE 5. Carolina-Semmes grading scale

\begin{tabular}{lccc}
\hline & \multicolumn{3}{c}{ No. of Points } \\
\cline { 2 - 4 } \multicolumn{1}{c}{ Preop Variables } & $\begin{array}{c}\text { Extended } \\
\text { LOS Scale } \\
(0-12)\end{array}$ & $\begin{array}{c}\text { Discharge to } \\
\text { Facility Scale } \\
(0-18)\end{array}$ & $\begin{array}{c}\text { 90-Day Hospital } \\
\text { Readmission } \\
(0-6)\end{array}$ \\
\hline Fusion & 3 & 3 & 2 \\
\hline ASA class $>$ III & 2 & 4 & 2 \\
\hline Age $\geq 70$ yrs & 2 & 3 & 1 \\
\hline ODI $\geq 70$ & 2 & 2 & 1 \\
\hline Diabetes & 1 & 2 & $0-6$ \\
\hline $\begin{array}{l}\text { Nonindependent am- } \\
\text { bulation }\end{array}$ & 2 & 2 & \\
\hline Nonprivate insurance & \multicolumn{3}{c}{2} \\
\hline Total score & $0-12$ & $0-18$ & \\
\hline
\end{tabular}

hospital systems. Furthermore, when applied to 2 separate neurosurgical practices for validation, the CarolinaSemmes scale again effectively stratified risk of extended LOS, readmission, and inpatient rehabilitation. As these events substantially contribute to increased costs of care, this novel scale may be used to understand financial risk when various patient populations are considered for inclusion in value-based or capitated payment models for elective spine surgery.

The risk factors identified in our study and supporting the Carolina-Semmes Scale are consistent with those previously reported in the literature to date. Various investigators have reported that advanced age is associated with a higher likelihood of comorbidities, complications, and longer recovery times following surgery, resulting in increased rehabilitation and skilled nursing needs postoperatively. ${ }^{13,14}$ In our analysis, advanced age was associated with higher odds of extended hospital LOS and need for inpatient rehabilitation. Similarly, Deyo et al. ${ }^{15}$ demonstrated that the risk discharge to an inpatient facility increased 4.2 times for every 10-year increment in age.

Few prior studies have reported the association between old age and readmission. Wang et al. ${ }^{46}$ queried the Medicare claims database and found 30-day readmission rates of $7.9 \%$ for cervical surgery and $7.3 \%$ for lumbar surgery. Factors found to be associated with a higher risk of readmission in their analysis were older age, more comorbidities, dual eligibility for Medicare/Medicaid, and a greater number of fused levels. Given that the Medicare population by definition represents an older cohort, data from this source may have limited generalizability. Kim et al. ${ }^{27}$ reviewed the NSQIP (National Surgical Quality Improvement Program) database for patients undergoing lumbar decompression and found a $4.4 \%$ rate of readmission. Older age was not a significant predictor of readmission in their analysis. Similarly, in our analysis utilizing prospectively collected multicenter registry data, older age was not an important predictor of 90-day readmission.

Several prior studies conducted on patients undergoing hip and knee arthroplasty identified that the presence of medical comorbidities is a key factor associated with longer hospital stay, complications, and discharge to rehabilitation facility and readmission. ${ }^{12,16,24,29,34}$ ASA class is 


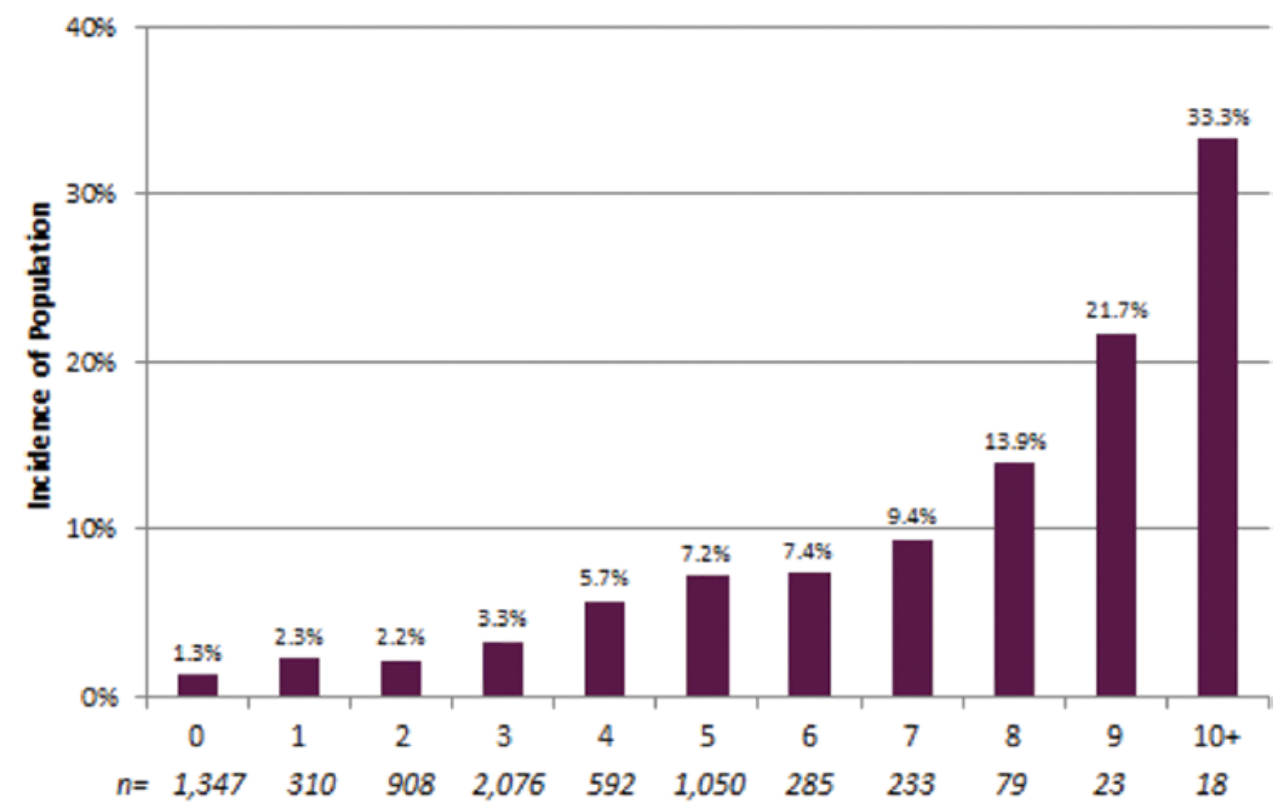

FIG. 1. Bar chart showing the incidence rates of extended LOS (> 7days) after elective 1- to 3-level lumbar surgery based on the Carolina-Semmes grading scale (Grade 0-12) within the QOD data set. Grade 0-3 patients had very little likelihood of extended LOS, while Grade 8-12 patients had a significant likelihood. Figure is available in color online only.

a method commonly used to describe preoperative global health and comorbidity status. In our analysis, the patients with comorbidities (ASA class > III and patients with diabetes) were more likely to have an extended LOS and need a longer recovery time, requiring discharge to inpatient rehabilitation or a skilled nursing facility. As an example, patients with diabetes might have a longer wound recovery time and require greater postdischarge needs as they continue to recover. ${ }^{8,20,22}$
Patients with a preoperative nonambulatory status and those who are ambulatory with an assistive device have greater needs for rehabilitation and longer recovery time than patients who are ambulatory preoperatively. $1,10,11,30$ Preoperative ambulatory status accurately reflects the severity of disability in most patients with spinal disorders. Theoretically, patients unable to walk independently will have higher ODI scores (i.e., worse disability). Indeed, in our analysis the patients with higher baseline ODI scores

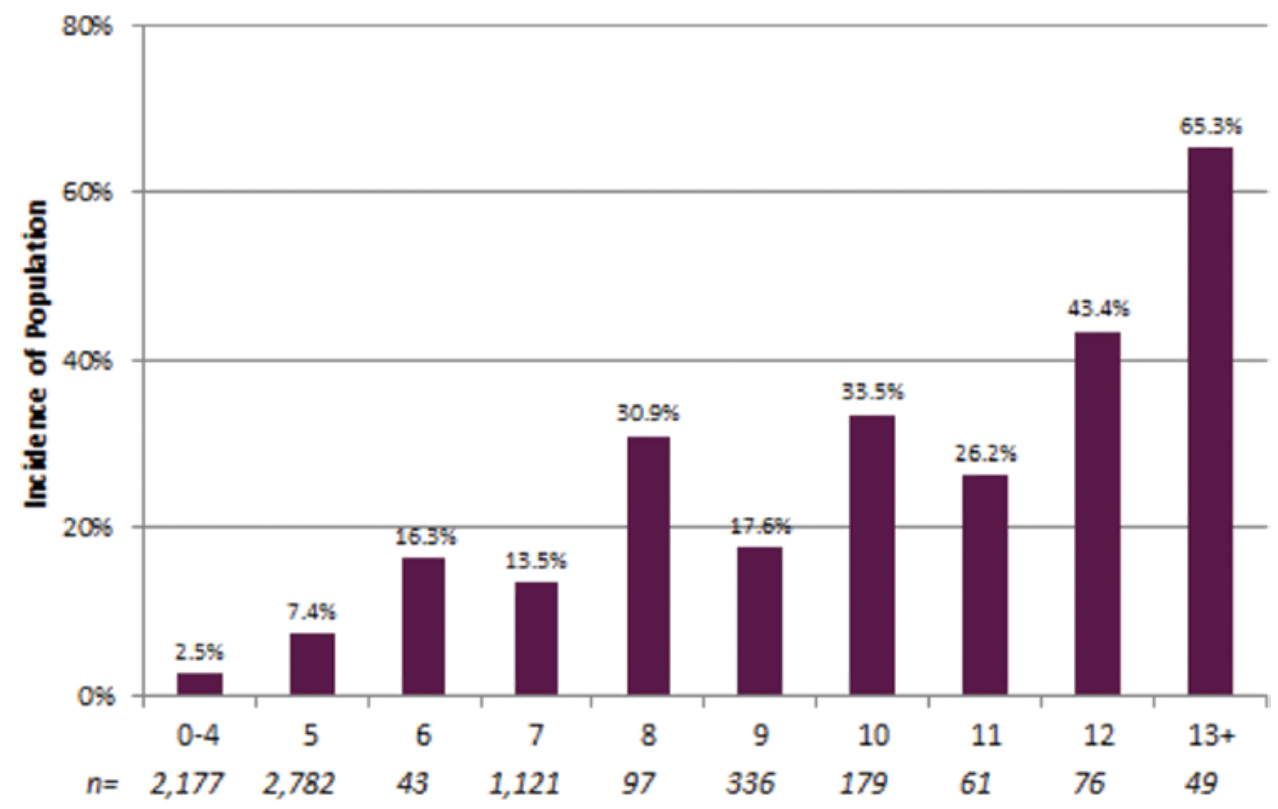

FIG. 2. Bar chart showing the incidence rates of discharge to rehabilitation facility after 1- to 3-level elective lumbar surgery based on the Carolina-Semmes grading scale (Grades 0-18) within the QOD data set. Grade 0-5 patients had very little likelihood of discharge to facility, while Grade 10-18 patients had a significant likelihood. Figure is available in color online only. 


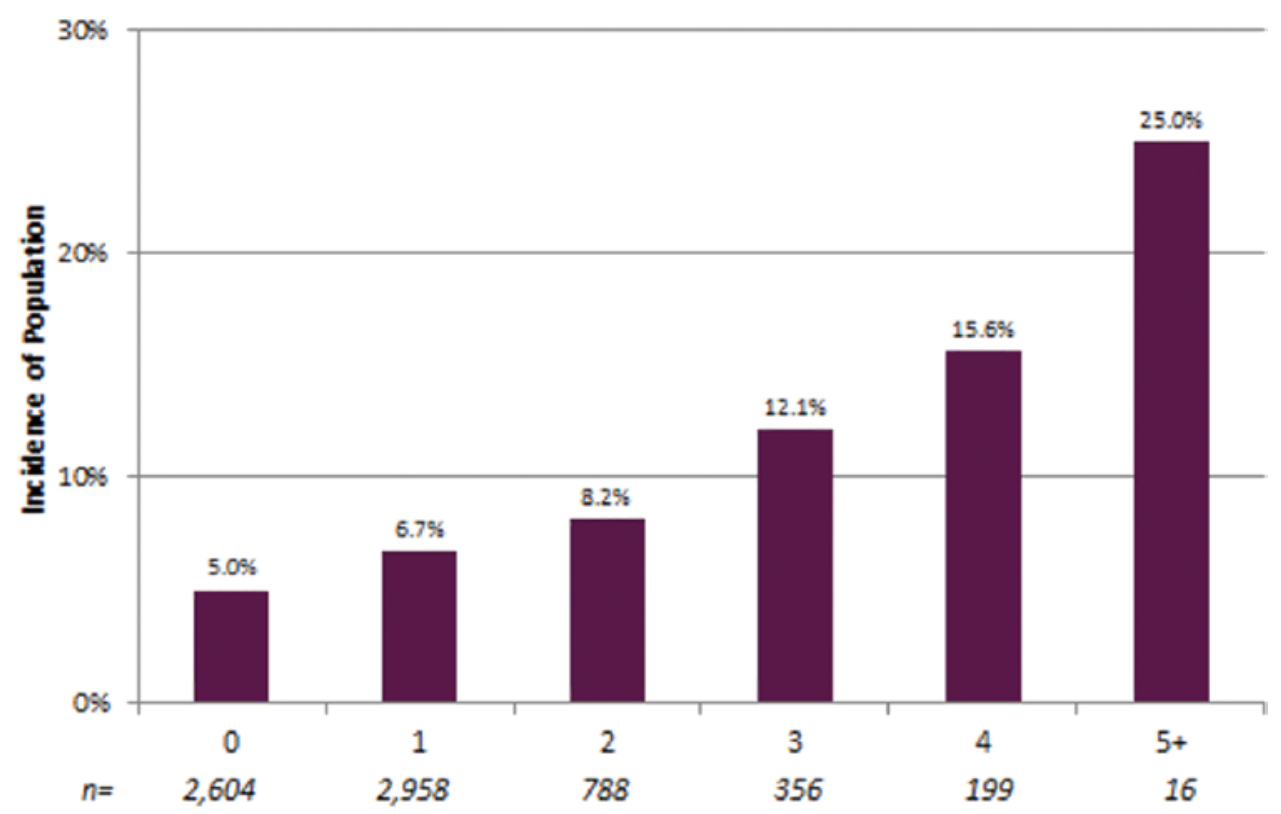

FIG. 3. Bar chart showing the incidence rates of 90 -day readmission after 1 - to 3 -level elective lumbar surgery according to the Carolina-Semmes grading scale (Grade 0-6) within the QOD data set. Incidence of 90-day readmission was 5-fold higher in Grade $5-6$ vs Grade $0-2$ patients. Figure is available in color online only.

were more likely to have extended LOS, need for discharge to a rehabilitation facility, and experience 90-day readmission. Analogous to our findings, Kannan et al., ${ }^{25}$ in a retrospective study of 339 patients undergoing lumbar laminectomy, reported that worse preoperative functional status is associated with longer LOS and a higher probability of being discharged to inpatient rehabilitation.

Patients undergoing fusion surgery versus laminectomy alone are more likely to have extended LOS and need for rehabilitation. Increased surgical invasiveness and complexity increases postoperative recovery time and need for assistance with inpatient rehabilitation. ${ }^{15,25,32}$ Interestingly, patients undergoing fusion versus decompression alone did not have a higher risk of 90-day readmission. Therefore, fusion appears to result in increased health care resource utilization related to inpatient resource utilization and longer recovery, but it does not seem to generate increased costs related to risk for 90-day readmission.

Consistent with previous studies, we found that the patients with Medicare/Medicaid insurance had a higher risk of postoperative unplanned events compared with those with private insurance.

The proposed Carolina-Semmes grading scale is intended to prospectively identify "high-risk" patients requiring surgery, so that appropriate interventions can be instituted preoperatively and immediately postoperatively to help reduce the incidence of unplanned events. Patients with higher comorbidities (ASA class > III), a history of diabetes, higher baseline disability (ODI score $\geq 70$ ), nonindependent ambulation, nonprivate insurance, elderly (age $\geq 70$ years), and patients undergoing fusion had a higher likelihood of having these unplanned events after elective surgery for degenerative lumbar diagnosis. Each of these factors has an additive effect on increased odds of having the adverse events. The patients with lower grades on the Carolina-Semmes grading scale are less likely to have any adverse events, and those with higher grades are more likely to have adverse events. The risk for each adverse event can be graded separately using the same tool (Figs. 1-3 and Table 5). Surgeons can use these factors to have a discussion with patients regarding the risk of having these unplanned events. Analyses such as these can also allow hospitals and surgeons to risk-stratify their practices to allow for more appropriate third-party evaluations of patient outcomes. Furthermore, understanding and accurately predicting which patients may require additional resource utilization within a global period after surgery may help facilitate the creation and implementation of risk-adjusted bundled payment systems that would more fairly compensate surgeons and hospitals for advanced services. Otherwise, hospitals and providers operating under bundled or capitated payment models may be incentivized to avoid risk, hindering patient's access to much-needed surgical care. Regular use of such a predictive tool can lead to more informed decision making when discussing treatment options and expectations with patients.

\section{Limitations}

Due to the limited sample size for each diagnosis, the patients with different diagnoses and procedures were pooled together into one model. The analyses would be more helpful if they were stratified by diagnosis and/or procedure. As more patients are enrolled, separate analyses for each diagnosis as well as for fusion versus nonfusion procedures can be conducted. Nonetheless, all attempts were made to account for the heterogeneity of the patient population. All baseline and surgery variables including fusion versus nonfusion were included in the model. Therefore, the reported odds ratios are adjusted for 

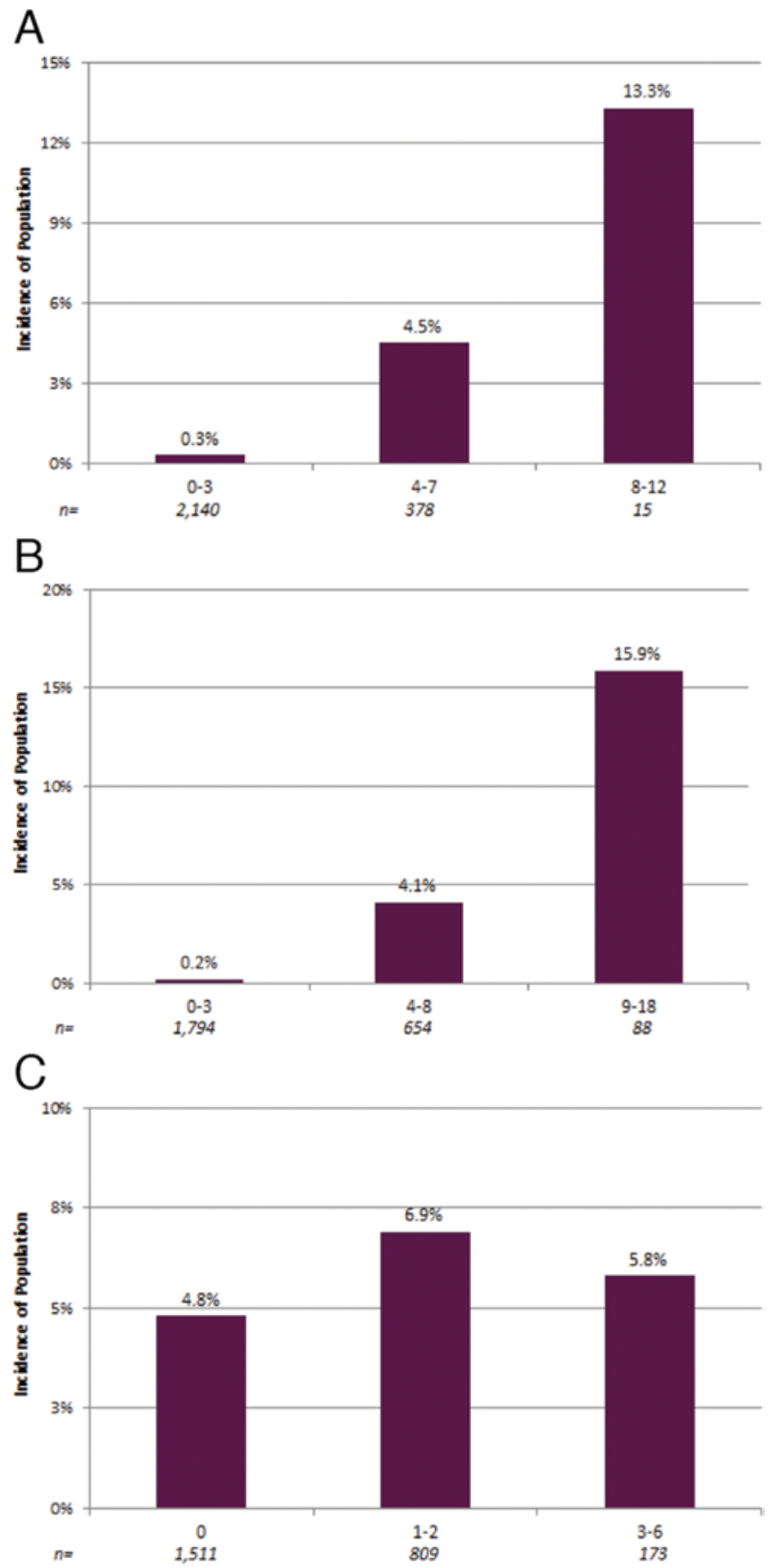

FIG. 4. Bar chart incidence rates of extended LOS (A), discharge to rehabilitation facility (B), and 90-day hospital readmission (C) after elective 1- to 3-level lumbar surgery per the Carolina-Semmes grading scale for patients treated at Carolina Neurosurgery \& Spine Associates (Charlotte, NC) and Semmes-Murphey Clinic (Memphis, TN). Figure is available in color online only.

all the aforementioned variables, meaning for 2 patients with similar preoperative variables, comorbidities, and surgery variables, patients with an ODI score $\geq 70$ will have a higher odds of the adverse events. An intrinsic limitation of predictive model-based analysis is the number of variables that are inputted into the model. Our models for extended LOS, need for rehabilitation, and 90-day readmission were adjusted for an array of patient-specific and surgery-specific factors; however, several other factors, including family support, marital status, and socioeconomic status, that may influence the unplanned events examined here are not collected in the registry and hence were not included in the models. ${ }^{26,36,38,41}$ The model was adjusted for race, educational level, and occupation, which partly accounts for patients' social status.

Despite the limitations inherent in the existing data, we have been able to construct a robust predictive model and novel grading scale to risk-stratify patients based on their probability of extended LOS, discharge to inpatient rehabilitation facility, and 90-day readmission, utilizing prospectively collected patient data from 74 centers in 26 states across the country. The primary advantage of welldesigned registries from a scientific perspective relates to their strong validity, which is achieved through an inclusive design that seeks to evaluate heterogeneous populations. As a result, the observed outcomes from multisite national registry analyses are often more representative of what is achieved in real-world practice and can more reliably be generalized to broader patient populations than other prospective data collection tools such as randomized controlled trials (which are characterized by narrow inclusion criteria). Hence, the performance of this risk-stratifying grading scale was easily reproducible when applied to 2 individual centers in this study.

\section{Conclusions}

For patients undergoing first-time elective 1- to 3-level degenerative lumbar spine surgery, we introduce the Carolina-Semmes grading scale that effectively stratifies risk of prolonged hospital stay, need for postdischarge inpatient facility care, and 90-day hospital readmission. This grading scale may be helpful for identifying the patients who may require additional resource utilization within a global period after surgery.

\section{References}

1. Adogwa O, Parker SL, Shau DN, Mendenhall SK, Bydon A, Cheng JS, et al: Preoperative Zung depression scale predicts patient satisfaction independent of the extent of improvement after revision lumbar surgery. Spine J 13:501-506, 2013

2. Akamnonu C, Cheriyan T, Goldstein JA, Lafage V, Errico TJ, Bendo JA: Unplanned hospital readmission after surgical treatment of common lumbar pathologies: rates and causes. Spine (Phila Pa 1976) 40:423-428, 2015

3. Akins PT, Harris J, Alvarez JL, Chen Y, Paxton EW, Bernbeck J, et al: Risk factors associated with 30-day readmissions after instrumented spine surgery in 14,939 patients: 30-day readmissions after instrumented spine surgery. Spine (Phila Pa 1976) 40:1022-1032, 2015

4. Amin BY, Tu TH, Schairer WW, Na L, Takemoto S, Berven S, et al: Pitfalls of calculating hospital readmission rates based on nonvalidated administrative data sets: presented at the 2012 Joint Spine Section Meeting: clinical article. J Neurosurg Spine 18:134-138, 2013

5. Asher AL, McCormick PC, Selden NR, Ghogawala Z, McGirt MJ: The National Neurosurgery Quality and Outcomes Database and NeuroPoint Alliance: rationale, development, and implementation. Neurosurg Focus 34(1):E2, 2013

6. Asher AL, Speroff T, Dittus RS, Parker SL, Davies JM, Selden N, et al: The National Neurosurgery Quality and Outcomes Database ( $\left.{ }^{2} \mathrm{QOD}\right)$ : a collaborative North American 
outcomes registry to advance value-based spine care. Spine (Phila Pa 1976) 39 (22 Suppl 1):S106-S116, 2014

7. Aujesky D, Mor MK, Geng M, Stone RA, Fine MJ, Ibrahim SA: Predictors of early hospital readmission after acute pulmonary embolism. Arch Intern Med 169:287-293, 2009

8. Bekelis K, Desai A, Bakhoum SF, Missios S: A predictive model of complications after spine surgery: the National Surgical Quality Improvement Program (NSQIP) 2005-2010. Spine J 14:1247-1255, 2014

9. Bekelis K, McGirt MJ, Parker SL, Holland CM, Davies J, Devin CJ, et al: The present and future of quality measures and public reporting in neurosurgery. Neurosurg Focus 39(6):E3, 2015

10. Chotai S, Sivaganesan A, Parker SL, McGirt MJ, Devin CJ: Patient-specific factors associated with dissatisfaction after elective surgery for degenerative spine diseases. Neurosurgery 77:157-163, 2015

11. De la Garza-Ramos R, Bydon M, Abt NB, Sciubba DM, Wolinsky JP, Bydon A, et al: The impact of obesity on short- and long-term outcomes after lumbar fusion. Spine (Phila Pa 1976) 40:56-61, 2015

12. de Pablo P, Losina E, Phillips CB, Fossel AH, Mahomed N, Lingard EA, et al: Determinants of discharge destination following elective total hip replacement. Arthritis Rheum 51:1009-1017, 2004

13. Devin CJ, Chotai S, Parker SL, Tetreault L, Fehlings MG, McGirt MJ: A cost-utility analysis of lumbar decompression with and without fusion for degenerative spine disease in the elderly. Neurosurgery 77 (Suppl 4):S116-S124, 2015

14. Deyo RA, Cherkin DC, Loeser JD, Bigos SJ, Ciol MA: Morbidity and mortality in association with operations on the lumbar spine. The influence of age, diagnosis, and procedure. J Bone Joint Surg Am 74:536-543, 1992

15. Deyo RA, Mirza SK, Martin BI, Kreuter W, Goodman DC, Jarvik JG: Trends, major medical complications, and charges associated with surgery for lumbar spinal stenosis in older adults. JAMA 303:1259-1265, 2010

16. Dillingham TR, Yacub JN, Pezzin LE: Determinants of postacute care discharge destination after dysvascular lower limb amputation. PM R 3:336-344, 2011

17. EuroQol Group: EuroQol-a new facility for the measurement of health-related quality of life. Health Policy 16:199208, 1990

18. Fairbank JC, Pynsent PB: The Oswestry Disability Index. Spine (Phila Pa 1976) 25:2940-2952, 2000

19. Garrison GM, Mansukhani MP, Bohn B: Predictors of thirtyday readmission among hospitalized family medicine patients. J Am Board Fam Med 26:71-77, 2013

20. Golinvaux NS, Varthi AG, Bohl DD, Basques BA, Grauer $\mathrm{JN}$ : Complication rates following elective lumbar fusion in patients with diabetes: insulin dependence makes the difference. Spine (Phila Pa 1976) 39:1809-1816, 2014

21. Gruskay JA, Fu M, Bohl DD, Webb ML, Grauer JN: Factors affecting length of stay after elective posterior lumbar spine surgery: a multivariate analysis. Spine J 15:1188-1195, 2015

22. Guzman JZ, Skovrlj B, Shin J, Hecht AC, Qureshi SA, Iatridis JC, et al: The impact of diabetes mellitus on patients undergoing degenerative cervical spine surgery. Spine (Phila Pa 1976) 39:1656-1665, 2014

23. Harris PA, Taylor R, Thielke R, Payne J, Gonzalez N, Conde JG: Research electronic data capture (REDCap) - a metadata-driven methodology and workflow process for providing translational research informatics support. J Biomed Inform 42:377-381, 2009

24. Jones CA, Voaklander DC, Johnston DW, Suarez-Almazor ME: The effect of age on pain, function, and quality of life after total hip and knee arthroplasty. Arch Intern Med 161:454-460, 2001

25. Kanaan SF, Yeh HW, Waitman RL, Burton DC, Arnold PM,
Sharma NK: Predicting discharge placement and health care needs after lumbar spine laminectomy. J Allied Health 43:88-97, 2014

26. Kersting RC: Impact of social support, diversity, and poverty on nursing home utilization in a nationally representative sample of older Americans. Soc Work Health Care 33:6787, 2001

27. Kim BD, Smith TR, Lim S, Cybulski GR, Kim JY: Predictors of unplanned readmission in patients undergoing lumbar decompression: multi-institutional analysis of 7016 patients. J Neurosurg Spine 20:606-616, 2014

28. Langley GB, Sheppeard H: The visual analogue scale: its use in pain measurement. Rheumatol Int 5:145-148, 1985

29. Mahomed NN, Koo Seen Lin MJ, Levesque J, Lan S, Bogoch ER: Determinants and outcomes of inpatient versus home based rehabilitation following elective hip and knee replacement. J Rheumatol 27:1753-1758, 2000

30. McGirt MJ, Sivaganesan A, Asher AL, Devin CJ: Prediction model for outcome after low-back surgery: individualized likelihood of complication, hospital readmission, return to work, and 12-month improvement in functional disability. Neurosurg Focus 39(6):E13, 2015

31. McGirt MJ, Speroff T, Dittus RS, Harrell FE Jr, Asher AL: The National Neurosurgery Quality and Outcomes Database $\left(\mathrm{N}^{2} \mathrm{QOD}\right)$ : general overview and pilot-year project description. Neurosurg Focus 34(1):E6, 2013

32. Mirza SK, Deyo RA, Heagerty PJ, Konodi MA, Lee LA, Turner JA, et al: Development of an index to characterize the "invasiveness" of spine surgery: validation by comparison to blood loss and operative time. Spine (Phila Pa 1976) 33:2651-2662, 2008

33. Modhia U, Takemoto S, Braid-Forbes MJ, Weber M, Berven SH: Readmission rates after decompression surgery in patients with lumbar spinal stenosis among Medicare beneficiaries. Spine (Phila Pa 1976) 38:591-596, 2013

34. Munin MC, Kwoh CK, Glynn N, Crossett L, Rubash HE: Predicting discharge outcome after elective hip and knee arthroplasty. Am J Phys Med Rehabil 74:294-301, 1995

35. Ness D, Kramer W: Reducing hospital readmissions: it's about improving patient care. Health Affairs Blog. August 16, 2013. (http://healthaffairs.org/blog/2013/08/16/reducinghospital-readmissions-its-about-improving-patient-care/) [Accessed February 2, 2017]

36. Nguyen TA, Page A, Aggarwal A, Henke P: Social determinants of discharge destination for patients after stroke with low admission FIM instrument scores. Arch Phys Med Rehabil 88:740-744, 2007

37. Parker SL, McGirt MJ, Bekelis K, Holland CM, Davies J, Devin CJ, et al: The National Neurosurgery Quality and Outcomes Database Qualified Clinical Data Registry: 2015 measure specifications and rationale. Neurosurg Focus 39(6):E4, 2015

38. Parkes J, Shepperd S: Discharge planning from hospital to home. Cochrane Database Syst Rev (4):CD000313, 2000

39. Pelton MA, Phillips FM, Singh K: A comparison of perioperative costs and outcomes in patients with and without workers' compensation claims treated with minimally invasive or open transforaminal lumbar interbody fusion. Spine (Phila Pa 1976) 37:1914-1919, 2012

40. Peng CW, Yue WM, Poh SY, Yeo W, Tan SB: Clinical and radiological outcomes of minimally invasive versus open transforaminal lumbar interbody fusion. Spine (Phila Pa 1976) 34:1385-1389, 2009

41. Preston DB: Marital status, gender roles, stress, and health in the elderly. Health Care Women Int 16:149-165, 1995

42. Schairer WW, Carrer A, Deviren V, Hu SS, Takemoto S, Mummaneni $\mathrm{P}$, et al: Hospital readmission after spine fusion for adult spinal deformity. Spine (Phila Pa 1976) 38:16811689,2013 
43. Sharma M, Sonig A, Ambekar S, Nanda A: Discharge dispositions, complications, and costs of hospitalization in spinal cord tumor surgery: analysis of data from the United States Nationwide Inpatient Sample, 2003-2010. J Neurosurg Spine 20:125-141, 2014

44. Siemionow K, Pelton MA, Hoskins JA, Singh K: Predictive factors of hospital stay in patients undergoing minimally invasive transforaminal lumbar interbody fusion and instrumentation. Spine (Phila Pa 1976) 37:2046-2054, 2012

45. Vaziri S, Cox JB, Friedman WA: Readmissions in neurosurgery: a qualitative inquiry. World Neurosurg 82:376-379, 2014

46. Wang MC, Shivakoti M, Sparapani RA, Guo C, Laud PW, Nattinger AB: Thirty-day readmissions after elective spine surgery for degenerative conditions among US Medicare beneficiaries. Spine J 12:902-911, 2012

47. Yeom JS, Buchowski JM, Shen HX, Liu G, Bunmaprasert T, Riew KD: Effect of fibrin sealant on drain output and duration of hospitalization after multilevel anterior cervical fusion: a retrospective matched pair analysis. Spine (Phila Pa 1976) 33:E543-E547, 2008

48. Zheng F, Cammisa FP Jr, Sandhu HS, Girardi FP, Khan SN: Factors predicting hospital stay, operative time, blood loss, and transfusion in patients undergoing revision posterior lumbar spine decompression, fusion, and segmental instrumentation. Spine (Phila Pa 1976) 27:818-824, 2002

\section{Disclosures}

The authors report no conflict of interest concerning the materials or methods used in this study or the findings specified in this paper.

\section{Author Contributions}

Conception and design: McGirt, Parker, Sorenson, Foley, Asher. Acquisition of data: Chotai, Pfortmiller. Analysis and interpretation of data: McGirt, Pfortmiller. Drafting the article: McGirt, Parker, Chotai. Critically revising the article: McGirt, Parker, Chotai, Foley, Asher. Reviewed submitted version of manuscript: McGirt, Parker, Chotai, Sorenson, Foley, Asher. Statistical analysis: Pfortmiller. Study supervision: McGirt, Asher.

\section{Correspondence}

Matthew J. McGirt, Department of Neurological Surgery, Carolina Neurosurgery and Spine Associates, 225 Baldwin Rd., Charlotte, NC 28204. email: matt.mcgirt@cnsa.com. 